\title{
An Empirical Study of the Relationship between Agriculture Environmental Efficiency and Economic Growth*
}

\author{
Xiaobo Wei, Jue Peng, Lu Cao \\ College of Economics and Management, Southwest University, Chongqing, China \\ Email: 584402403@qq.com
}

Received 26 March 2014; revised 26 April 2014; accepted 10 May 2014

Copyright (C) 2014 by authors and Scientific Research Publishing Inc.

This work is licensed under the Creative Commons Attribution International License (CC BY).

http://creativecommons.org/licenses/by/4.0/

(c) (i) Open Access

\begin{abstract}
According to environmental Kuznets hypothesis, inverted "U" relationship exists between environmental quality and economic development. Along with economic growth, environmental quality will be presented a trend that first gets worsening and then gets improved [1]. The agricultural environment efficiency will be presented a trend that first decreases and then increases along with agricultural nonpoint source pollution changes at different stages of economic development [2]. In order to verify whether such relationship exists in various provinces of China's agricultural production, this paper is based on accounting for agriculture pollution emissions per province of China, and calculates the agriculture environmental efficiency in various provinces of China of 20 years in 1992-2011 based on SBM model. On this basis, further study on the relationship between the agriculture environmental efficiency and economic growth has been done. The result shows that causal relationship exists between agriculture environmental efficiency and China's economic growth, and the curve between agriculture environmental efficiency and economic growth is showing "U" shape, indirectly verified the EKC hypothesis.
\end{abstract}

\section{Keywords}

Agriculture Environmental Efficiency, Economic Growth, SBM Model

\section{Introduction}

As a large agricultural country, agriculture economic development has always been a focus of China's economic

"This paper is the initial result of general project of central university basic research (project number: SWU1309246). 
development [3]. However, with the rapid economic growth, on one hand, the development and utilization of resources are growing and the investment in modern agricultural production factors is increasing, which has exceeded the carrying capacity of environment itself, causing serious pollution to the environment; on the other hand, the excessive consumption of resources and environment's deteriorating will affect the sustainable development of economic. The relationship between economic development and agriculture ecological environment is often contradictory, in which the major contradiction is the contradiction between economic growth's infinite demand on agricultural resources and limited supply of agricultural resources [4]. Without economic development, agriculture environmental issues will not be solved; and without agriculture environmental and resource issues be solved, it is difficult to maintain sustainable economic development.

Due to the pesticide and fertilizer application techniques are not standardized, turnover rates of fertilizer are high, only about $1 / 3$ are absorbed by crops, far beyond the upper limit of safety standard in developed countries [5]. Currently the main way to increase agricultural output is a large number of inputs of chemical fertilizers, pesticides and plastic sheeting and other factors of production, which increase the pressure on agricultural nonpoint source pollution [3]. Increasing the scale of livestock farming has solved the effective supply of urban and rural markets of animal products to a certain extent, but also in large part, has caused the seriously impact on the surrounding environment. There are about 1.73 billion tons excrements of livestocks produced in China annually, and such pollution is the most common kind of pollution of livestock pollution. Nitrogen, phosphorus and hydrocarbons in manure go into water by erosion, which is likely to cause biochemical oxygen demand, chemical oxygen demand index to rise. In addition, China has about 1.77 billion tons annual production of straw, the straw sources including wheat straw, rice straw, yellow dry corn stalks, etc., and "the burning of straw" pollution problem in rural areas is the main problem China is facing in agriculture sustainable development.

According to Kuznets inverted " $U$ " hypothesis, at the early stage of economic development the pollutant emissions increase with economic development, when the economy is developed to a certain stage pollutant emissions decreases with further development of the economy. That is to say in a country or region, the pollutant emissions of economic development in different time periods will inevitably experience a process that first increase and then decrease. And agriculture environmental efficiency will show the change that first decreases and then increases with changes of agricultural nonpoint source pollution in different economic development stages. In order to verify whether such relationship exists in various provinces of China's agricultural production, this paper is based on accounting for agriculture pollution emissions per province of China, using relevant model to calculate the agriculture environmental efficiency in various provinces of China of 20 years in 1992-2011. Through co-integration analysis and Granger test, it examines and analyzes the internal relation between economic development and changes of agriculture environmental efficiency. Finally, on the basis of argument of co-integration relationship exists between economic development and agriculture environmental efficiency, it uses panel data from all provinces of China to examine the relationship between economic growth and agriculture environmental efficiency and the shape of curve, and tries to indirectly verify the EKC hypothesis.

\subsection{Definition of Concept}

\section{Environmental Efficiency [6]}

The concept of environmental efficiency can be traced back to the 1970s (Freeman), and there were two statements-“environmental efficiency" and "eco-efficiency". In 1992, the World Business Council for Sustainable Development (WBCSD) treated eco-efficiency as a business concept for the first time, and pointed out that enterprises should combine environmental and economic development, to face the challenges of sustainable development, proposed that environmental efficiency refers to the ratio of the economic value of products and services to meet human needs and the environmental load, that is, the unit economic value of environmental load; In 1998, OECD extended this concept to government, industrial enterprises and other organizations, and pointed out that the ecological efficiency is a kind of efficiency to measure biological resources meet human needs; the efficiency value is the ratio of the economic value of products or services and the sum of the environmental pollution or destruction produced in production. In addition, some scholars have measured the environmental efficiency, that environmental efficiency is the ratio of the smallest possible value of a variety of harmful inputs and actual usage; environmental performance is the ratio of the added value and the resulting environmental damage loss. These references are from both economic and environmental aspects, environmental efficiency value is the ratio of added economic value and environmental impact, and it is the comprehensive measurement of the envi- 
ronmental impact of resource use and economic activities. Environmental efficiency evaluation is concerned about the impact of the production process evaluated on the environment, and it also evaluates the economic value of the production activities, namely, economic and environmental benefits.

Combined with the current definition and calculation method on the concept of environmental efficiency, a definition of agriculture environmental efficiency is given tentatively: agriculture environmental efficiency refers to take each province or region as a decision-making unit, in the same period, and in the agricultural production of an decision-making unit, the ratio of the economic value of products and services meets human demand and the environmental pollution and destruction loss from this.

\subsection{Environmental Efficiency Evaluation Methodology}

From the research literature [7]-[21], the research of environmental efficiency still focuses on the non-parametric DEA technical aspects, while the research for the statistical properties of non-parametric DEA efficiency model with consideration of undesirable outputs is still rare. The domestic and foreign scholars' research mainly focused on the environmental efficiency of industry, and the research on agriculture environmental efficiency is relatively few. Therefore, this paper is based on accounting for agriculture pollution emissions per province of China, studies the agriculture environmental efficiency, and makes correlation analysis on agriculture environmental efficiency and economic growth.

Environmental efficiency evaluation began with researchers' concerns on limiting carbon dioxide emissions generated in the process of energy use; then some researchers began to concern the reduction of greenhouse gas emissions, and had given the multi-objective decision analysis model and ICLIPS evaluation methods and so on. These methods are summed up: life cycle method, multi-criteria decision making method, stochastic analysis method, distance function method, and data envelopment analysis method [7] [8] [13]-[15] [18]. In 1989 Fare proposed the data envelopment analysis model to evaluate the environmental efficiency, attracting a large number of scholars to research theoretical modeling and application of environmental efficiency, greatly enriched the theoretical system, and expanded the scope of application of data envelopment analysis [22] [23]. This paper based on SBM model established by Tone (2001), an environmental efficiency evaluation model containing non-desired output has been built, overall considering the effects of inputs, expected outputs and undesirable outputs on environmental efficiency.

\section{Model and Data}

SBM model Tone has two important features:

1) The results of efficiency measure is not affected by the measuring unit used in the input and output items.

2) Efficiency value and each is monotone decreasing the difference between the input and output.

For there are $m$ and $s$ kind of input-output production, we can get production may be set:

$$
P=\{(\mathbf{x}, \mathbf{y}) \mid \mathbf{x} \geq \mathbf{X} \lambda, \mathbf{y} \leq \mathbf{Y} \lambda, \lambda \geq 0\}
$$

The basic form of SBM model:

$$
\begin{gathered}
\rho^{*}=\min \frac{1-\frac{1}{m} \sum_{k=1}^{m} s_{k}^{-} / x_{i o}}{1+\frac{1}{s}\left(\sum_{r=1}^{S} s_{r}^{+} / y_{r o}\right)} \\
\text { s.t. } \quad \mathbf{x}_{o}=\mathbf{X} \lambda+\mathbf{s}^{-} \\
\mathbf{y}_{o}=\mathbf{Y} \lambda-\mathbf{s}^{+} \\
\lambda \geq 0, \mathbf{s}^{-} \geq \mathbf{0}, \mathbf{s}^{+} \geq \mathbf{0},
\end{gathered}
$$

In the objective function of the model, $\frac{1}{m} \sum_{k=1}^{m} s_{k}^{-} / x_{k o}$ is the average of $m$ items into their actual mass ratio of redundancy, is $m$ items into average efficiency. Molecular is thus reflects the average efficiency of the in- 
vestment. $\frac{1}{s} \sum_{r=1}^{s} s_{r}^{+} / y_{r o}$ is the average of the shortage of the $s$ output ratio of their actual output, is the average of $s$ output efficiency levels. $\frac{1}{1+\frac{1}{s}\left(\sum_{r=1}^{s} s_{r}^{+} / y_{r o}\right)}$ said the efficiency level of output. In the SBM model, the value of the efficiency of each DMU input the average efficiency of level and the output of the average efficiency of the product. Input and output efficiency levels will affect SBM efficiency value.

The form of the objective function to model, we can see clearly, SBM model with the method of the ray type directly the slack variable is introduced into the objective function, relative to the linear way, because takes into account all the slack variables, can more accurately to evaluate the efficiency value.

We can observe that, for any $k, s_{k}^{-} \leq x_{k o}$ is always set up, thus $0 \leq s_{k}^{-} / x_{k o} \leq 1(k=1, \cdots, m)$, and only when the production does not require any input, just can have $s_{k}^{-} / x_{k o}=1$. So will get:

$$
0 \leq \frac{\sum_{i=1}^{m} s_{k}^{-} / x_{k o}}{m} \leq 1
$$

But this constraint relation for output is not set up, because of the lack of output may be larger than the actual output, but in any case will be:

$$
0 \leq \frac{\sum_{r=1}^{s} s_{r}^{+} / y_{r o}}{s}
$$

The environmental efficiency evaluation in this paper is based on the SBM model of Tone (2001), assuming that there are n DMUs, and DMUs use inputs to produce desired outputs and undesirable outputs, and then the model expression:

$$
\begin{gathered}
\rho^{*}=\min \frac{1-\frac{1}{m} \sum_{k=1}^{m} s_{k}^{-} / x_{i o}}{1+\frac{1}{s+t}\left(\sum_{r=1}^{s} s_{r}^{+} / y_{r o}+\sum_{p=1}^{t} s_{p}^{+} / b_{p o}\right)} \\
\text { s.t. } x_{o}=X \lambda+s_{k}^{-} \\
y_{o}=Y \lambda-s_{r}^{+} \\
b_{o}=B \lambda-\mathbf{s}_{P}^{+} \\
\lambda \geq 0, s_{k}^{-}, s_{r}^{+}, s_{p}^{+} \geq 0
\end{gathered}
$$

In the model, $\rho^{*}$ means that the efficiency value of DMU $\left(\mathbf{x}_{o}, \mathbf{y}_{o}\right), s_{k}^{-}$means the redundancy of $k$ kind of input, $s_{r}^{+}$means the shortage of $r$ kind of output, $s_{p}^{+}$means the handling capacity of undesirable outputs, $\lambda$ is adjustment matrix, $\mathbf{X} \lambda$ means the amount invested on the leading edge, $\mathbf{Y} \lambda$ means the outputs amount on the leading edge, $B \lambda$ means the undesirable outputs [13].

Since 1992, China’s economy has been developing rapidly; the agricultural economy has also been developed on a certain degree. But the agricultural nonpoint source pollution as also expect a undesired outputs is also substantially increasing, it can be said, in some regions in China, the agricultural development is acquired at the expense of the environment [3] [16] [17] [19]. We collected data from 1992 to 2011 of those 20 years. The input indicators are selected from labor of all provinces (the total labor force of agriculture, forestry, animal husbandry and fishery, excluding industry and services), land (total sown area), agricultural machinery (total power of agricultural machinery, excluding non-agricultural purposes), irrigation (actual effective irrigation area) and the amount of plastic film. The desired output is selected as each province's total output value of agriculture, forestry, animal husbandry and fishery at the end year. Undesired output is selected as the agricultural nonpoint source pollution in various provinces, and the selected indicators in this paper include fertilizer and pesticide 
pollution, agricultural solid waste pollution and animal excretion pollution.

The fertilizer and pesticide pollution emission indicator is expressed by input density, i.e. the amount of fertilizers and pesticides into crops per unit area. The agricultural solid waste pollution emissions indicator is expressed by the amount of straw produced per unit area of crop, in which, the ratio of gain production and straw amount is 1 to 1.5. The animal excretion pollution emission indicator is expressed by excretion density, i.e. the livestock manure excretion amount per unit arable land. Manure excretion amount = coefficient of annual excretion $\times$ number of breeding, drawing correlational research, the coefficient of annual livestock excretion is acquired (see: Table 1). The data sources in the study are on the basis of "China Statistical Yearbook", Statistical Yearbook of various provinces and database of National Statistics Bureau Statistics. Taking into account that Chongqing became a municipality in 1997, and therefore it was included in the Sichuan Province.

As can be seen from the Table 2, all kinds of nonpoint source pollution showed a growth trend over the years. It has proved that the agricultural economic growth is accompanied by heavy pollution in China. China just entered the mid-industrialization and agricultural nonpoint source pollution is a product of industrialization. The agricultural production form with features of high investment, high-pollution has completely replaced the earlier

Table 1. Coefficient of annual livestock excretion $\mathrm{kg} / \mathrm{head}$.

\begin{tabular}{cccccc}
\hline Pollutant & Live pig & Egg-laying poultry & Meat and poultry & Cow & Sheep \\
\hline Feces & 396 & 27.375 & 8.25 & 10,950 & 870 \\
Piss & 522 & $/$ & $/$ & 6570 & $/$ \\
\hline
\end{tabular}

Source: [24].

Table 2. The status of agricultural nonpoint source pollution $1992-2011 \mathrm{~kg} / \mathrm{hm}^{2}$.

\begin{tabular}{ccccc}
\hline $\begin{array}{c}\text { Pollution } \\
\text { year }\end{array}$ & $\begin{array}{c}\text { Fertilizer } \\
\text { input density }\end{array}$ & $\begin{array}{c}\text { Pesticide } \\
\text { input density }\end{array}$ & $\begin{array}{c}\text { Straw production } \\
\text { amount per unit area }\end{array}$ & $\begin{array}{c}\text { Livestock and poultry } \\
\text { excretion density }\end{array}$ \\
\hline 1992 & 196.6483 & 5.363328 & 6006 & 16317 \\
1993 & 213.34 & 5.718126 & 6196.5 & 17436.07 \\
1994 & 223.8186 & 6.6011 & 6094.5 & 19099.46 \\
1995 & 239.7729 & 7.252796 & 6360 & 20602.14 \\
1996 & 251.2065 & 7.486596 & 6724.5 & 17212.13 \\
1997 & 258.5387 & 7.764319 & 6565.5 & 18119.34 \\
1998 & 262.2704 & 7.910436 & 6753 & 19106.22 \\
1999 & 263.7479 & 8.451726 & 6739.5 & 19527.28 \\
2000 & 265.285 & 8.186399 & 6391.5 & 19904.44 \\
2001 & 273.1911 & 8.187255 & 6400.5 & 20099.27 \\
2002 & 280.6212 & 8.479676 & 6598.5 & 20753.14 \\
2003 & 289.4467 & 8.694855 & 6499.5 & 21826.03 \\
2004 & 301.9553 & 9.026408 & 6931.5 & 22331.46 \\
2005 & 306.5322 & 9.389455 & 6963 & 22827.04 \\
2006 & 313.8251 & 9.789181 & 7117.5 & 22448.14 \\
2007 & 332.834 & 10.57471 & 7122 & 18007.86 \\
2008 & 335.2623 & 10.70138 & 7426.5 & 17962.21 \\
2009 & 340.6691 & 10.77287 & 7305.828 & 17919.37 \\
2010 & 346.1464 & 10.94272 & 7460.362 & 7748.836 \\
2011 & 351.4966 & 11.01161 & & \\
\hline
\end{tabular}


traditional agriculture. On one hand, the agricultural production has greatly increased; on the other hand, has also resulted in the loss of soil fertility, severe soil erosion, desertification and salinization of soil and other ecological problems. In the initial stage of industrial development, due to the use of agricultural resources and agroindustrial products, agricultural producers must improve the efficiency of land use, the high-yield and highpolluting pesticides which can be partially replaced soil fertility are widely used. However, due to the development of backward industrial technology, these chemicals utilization efficiency is very low, the greater the loss, the more investment, resulting in growing nonpoint source pollution. Therefore, China is still in the phase that the development of industrialization and agricultural nonpoint source pollution keeps rising.

\section{Measurement Results Analysis}

Based on SBM model, treat various provinces as DMU, the agro-environmental efficiency values for each province has been calculated. Due to space limitation, here we only list the agricultural environmental efficiency value in 1992, 2001 and 2011.

From the Table 3, we can see that the provinces with high environmental efficiency are mainly concentrated in the eastern coastal regions, such as Beijing, Tianjin, Shanghai, Guangdong and Hainan, and relatively remote Tibet's efficiency value is high. And provinces which as major agricultural province Jiangxi, Shandong, Heilongjiang, Henan, Sichuan, Anhui, Hunan, Hebei, Jilin, etc. their agriculture environmental efficiency values are generally low. This may be because the economic development of coastal regions is early, major for industrial development, and relevant environmental protection and policies and measures are introduced, focusing on the impact on environment; Tibet as a remote western province, with slow economic development, and science and technology is relatively backward, meanwhile because of the geographical environment, the process of agriculture development is accompanied with less pollution, so the environmental efficiency is relatively high; while large agricultural provinces in the process of agriculture development, heavily relying on the use of pesticides and fertilizers and plastic sheeting, has brought more pollution in the rapid development of agricultural economy, so the agriculture environmental efficiency shows lower level.

Table 3. Agriculture environmental efficiency value for each province in 1992, 2001 and 2011.

\begin{tabular}{|c|c|c|c|c|c|c|c|}
\hline YMU & 1992 & 2001 & 2011 & YMear & 1992 & 2001 & 2011 \\
\hline Beijing & 1 & 1 & 1 & Henan & 0.314575 & 0.262984 & 0.44138 \\
\hline Tianjin & 0.691815 & 0.533265 & 0.563055 & Hubei & 0.444596 & 0.389205 & 1 \\
\hline Hebei & 0.278294 & 0.298632 & 0.483326 & Hunan & 0.397055 & 0.302596 & 0.601878 \\
\hline Shanxi & 0.230725 & 0.154885 & 0.325811 & Guangdong & 1 & 0.598682 & 1 \\
\hline Neimenggu & 0.334484 & 0.261642 & 0.459033 & Guangxi & 0.428978 & 0.304027 & 0.73698 \\
\hline Liaoning & 0.65187 & 0.513633 & 0.805621 & Hainan & 1 & 1 & 1 \\
\hline Jilin & 0.449502 & 0.361166 & 0.560785 & Sichuan & 0.478306 & 0.342819 & 0.56237 \\
\hline Heilongjiang & 0.542918 & 0.253254 & 0.51391 & Guizhou & 0.449998 & 0.257341 & 0.294528 \\
\hline Shanghai & 1 & 1 & 1 & Yunnan & 0.374151 & 0.244978 & 0.361555 \\
\hline Jiangsu & 0.502025 & 0.450421 & 1 & Xizang & 1 & 1 & 1 \\
\hline Zhejiang & 0.522356 & 0.490516 & 0.688708 & Shanxi & 0.319585 & 0.225636 & 0.565762 \\
\hline Anhui & 0.320381 & 0.258208 & 0.418614 & Gansu & 0.257909 & 0.191295 & 0.244399 \\
\hline Fujian & 0.667785 & 0.829891 & 0.89919 & Qinghai & 0.372631 & 0.34351 & 0.566172 \\
\hline Jiangxi & 0.429256 & 0.340082 & 0.459522 & Ningxia & 0.23591 & 0.173781 & 0.341084 \\
\hline Shandong & 0.438228 & 0.336101 & 0.487738 & Xinjiang & 0.474988 & 0.352144 & 0.431914 \\
\hline
\end{tabular}

Data sources: according to the official statistical data is obtained by calculation. 
We can learn from the table that the environmental efficiency values show first decrease and then increase. According to environmental economics theory, the experienced Environmental Kuznets hypothesis (EKC) exists between environmental quality and economic development, i.e. the curve of economic growth and environmental pollution has a feature of inverted "U"-type. Agricultural nonpoint source pollution is a result of economic development, the change that first increase and then decrease will be presented in different stages of economic development; and the agriculture environmental efficiency will show the change that first decrease and then increase along with the change of agricultural nonpoint source pollution at different stages of economic development.

The investigation for the intrinsic relationship between the national economic development and agriculture environmental efficiency includes the co-integration analysis and Granger causality test; on the basis of verifying there is co-integration relationship between agriculture environmental efficiency and economic development, use the panel data of all provinces to indirectly test EKC theory.

Economic growth: per capita GDP growth rate (Y).

Agriculture environmental efficiency: calculated based on SBM model (X).

From the Table 4, we can see that the $\mathrm{P}=0.0052$, should reject the null hypothesis that the data is not stable. It can be seen that the time series is stationary.

From the Table 5, we can see that the $\mathrm{P}=0.0002$, should reject the null hypothesis that the data is not stable. It can be seen that agriculture environmental efficiency is stationary.

Thus, according to Granger's co-integration theory. According to the original assumption of the $\mathrm{P}$ values, $\mathrm{P}=$ 0.4365 and 0.2266 , under the 0.05 significance level did not reject the null hypothesis, the co-integration relationship between economic growth and agriculture environmental efficiency does not exist, that is, in short term economic growth and agriculture environmental efficiency is not related (Table 6).

Whether there is long-term equilibrium relationship between economic development and between agriculture environmental efficiency, Granger causality Test need to be done.

\begin{tabular}{|c|c|c|c|}
\hline & & t-statistic & Prob. $^{*}$ \\
\hline \multicolumn{2}{|c|}{ Augmented Dickey-Fuller test statistic } & -4.370356 & 0.0052 \\
\hline \multirow[t]{3}{*}{ Test critical values: } & $1 \%$ level & -4.004425 & \\
\hline & 5\% level & -3.098896 & \\
\hline & $10 \%$ level & -2.690439 & \\
\hline
\end{tabular}

Table 5. Stationarity test for agriculture environmental efficiency.

\begin{tabular}{|c|c|c|c|}
\hline & & t-statistic & Prob. ${ }^{*}$ \\
\hline \multicolumn{2}{|c|}{ Augmented Dickey-Fuller test statistic } & -5.892359 & 0.0002 \\
\hline \multirow[t]{3}{*}{ Test critical values: } & $1 \%$ level & -3.857386 & \\
\hline & $5 \%$ level & -3.040391 & \\
\hline & $10 \%$ level & -2.660551 & \\
\hline
\end{tabular}

Table 6. Co-integration test.

\begin{tabular}{ccccc}
\hline Hypothesized & & Max-eigen & 0.05 & \\
No. of CE (s) & Eigenvalue & Statistic & Critical value & Prob. $^{* *}$ \\
\hline None & 0.339221 & 7.458038 & 14.26460 & 0.4365 \\
At most 1 & 0.078007 & 1.461916 & 3.841466 & 0.2266 \\
\hline
\end{tabular}


From the test results Table 7, according to the original assumption of the $\mathrm{P}$ values, $\mathrm{P}=0.0620$ and 0.0060 , under the 0.05 significance level reject null hypothesis: there is no causal relationship. It can be seen that economic growth $\mathrm{Y}$ is the Granger cause leading agriculture environmental efficiency $\mathrm{X}$ change, but also agriculture environmental efficiency $\mathrm{X}$ is the Granger cause of economic growth $\mathrm{Y}$. The above conclusion shows that there is bidirectional causality between China's per capita GDP change and agriculture environmental efficiency change.

The empirical survey for the long-term equilibrium relation and Granger causality between agriculture environmental efficiency and economic growth in China from 1992 to 2011 has been done, obtained the following timing relationships results: perform stationary test to the timing data, found that there is integration phenomenon in agriculture environmental efficiency and per capita GDP variable. Through Granger Causality Test methods the two-way causal relationship between agriculture environmental efficiency and per capita GDP has been investigated. It can be found that causal relationship exists between agriculture environmental efficiency and China's per capita GDP, showing that along with economic development, agriculture environmental efficiency is low and we are seeking economic growth with the loss of environmental protection. Change of economic growth is an important reason for nonpoint source pollution and environmental efficiency change. When the level of economic development is low, environmental degradation is also at a lower level; while economic development is accelerating into era of industrialization, along with the intensity of agriculture and other resource development increasing and the rise of large-scale machine industry, the resource consumption rate will exceed renewable resources rate, and the produced toxic waste pollution the quality of environment, making environmental degradation; but when the economy develops to a certain level, into the post-industrial era, clean industrial and economic structure is to be transformed, along with the improvement of consumer and environmental awareness, take a greater emphasis on implementation of environmental laws and regulations. The government has sufficient funds for technological innovation and environmental protection investment, thus the environmental quality will get improved.

In order to further examine the relationship between agriculture environmental efficiency and economic growth, while once again indirectly validate EKC hypothesis, use the panel data from all provinces to do further empirical test.

As can be seen from the Table 8 , according to the various inspection methods $\mathrm{P}$ values, $\mathrm{P}$ values are 0.0000 , under the 0.01 significance level declined to the original assumption: the data is not stable. The panel unit root of economic growth is steady.

From the Table 9, according to the various inspection methods $\mathrm{P}$ values, $\mathrm{P}$ values are 0.0000 , under the 0.01 significance level declined to the original assumption: the data is not stable. The panel unit root of agriculture environmental efficiency is also steady.

It can be found from the Table 10, according to the original assumption of the $\mathrm{P}$ values, $\mathrm{P}=0.0015$ and 0.0036, under the 0.01 significance level reject null hypothesis: there is no causal relationship. Bidirectional

Table 7. Granger causality test results of agriculture environmental efficiency and economic growth.

\begin{tabular}{ccc}
\hline Null hypothesis: & F-statistic & Prob. \\
\hline Y does not Granger Cause X & 5.48812 & 0.0620 \\
X does not Granger Cause Y & 20.3358 & 0.0060 \\
\hline
\end{tabular}

Table 8. Stationarity test for economic growth.

\begin{tabular}{ccccc}
\hline Method & Statistic & Prob. $^{* *}$ & $\begin{array}{c}\text { Cross- } \\
\text { sections }\end{array}$ & Obs \\
\hline Levin, Lin \& Chu t & -10.8676 & 0.0000 & 30 & 510 \\
Im, Pesaran and Shin W-stat & -11.5403 & 0.0000 & 30 & 510 \\
ADF-Fisher Chi-square & 243.082 & 0.0000 & 30 & 510 \\
PP-Fisher Chi-square & 458.944 & 0.0000 & 30 & 540 \\
\hline
\end{tabular}


causality exists between economic growth and agriculture environmental efficiency. This is aligned with the national data analysis results.

Further study the relationship between agriculture environmental efficiency and economic development, which is the relationship that first decrease and then increase and thus indirectly validate EKC theory.

According to Hausman test, according to the original assumption of the $\mathrm{P}$ values, $\mathrm{P}=0.0040$, under the 0.01 significance level declined to the original assumption: using random, so using fixed effects model, it can be seen from the regression equation of fixed effects: $X=97.70853+1.511859 \mathrm{Y}^{2}-0.746648 \mathrm{Y}$, the coefficient of $\mathrm{YY}=1.511859>0$, so the curve between agriculture environmental efficiency and economic growth is showing "U" shape, that is to say along with different economic development stages, agriculture environment efficiency showing the change that first decrease and then increase, and agricultural nonpoint source pollution the amount of pollution will show the change that first increase and then decrease in different stages of economic development. This has indirectly verified the EKC hypothesis (Table 11).

From the "U" shape of China's economic development and agriculture environmental efficiency, it can be seen that with the economic development, the agriculture environment efficiency level will gradually slow down and towards improvement. However, from the current status quo of view, there is still a certain distance away from the turning point, agricultural nonpoint source pollution still continues to deteriorate, and environmental efficiency of agriculture in most provinces stays at the left side of shaped "U". In recent years, due to agricultural nonpoint source pollution is more serious in China's economic development; the agriculture environment efficiency is getting increasingly low. Controlling agricultural nonpoint source pollution, improving the efficiency of agricultural environment, strengthening environmental policy intervention is the key, which includes not only economic structural adjustment and technological progress, but also need government to improve environmental management ability. Guide farmers according to the government's environmental policy, educating farmers greatly increase environmental awareness, taking into account agricultural environmental protection in production process, technology adoption will be more green and rationalized, such behavior is a necessary option to reduce the transition value and a lower inflection point.

Table 9. Stationarity test for agriculture environmental efficiency.

\begin{tabular}{ccccc}
\hline Method & Statistic & Prob. $^{* *}$ & $\begin{array}{c}\text { Cross- } \\
\text { sections }\end{array}$ & Obs \\
\hline Levin, Lin \& Chu t & -5.09550 & 0.0000 & 30 & 510 \\
Im, Pesaran and Shin W-stat & -9.16301 & 0.0000 & 30 & 510 \\
ADF-Fisher Chi-square & 196.802 & 0.0000 & 30 & 510 \\
PP-Fisher Chi-square & 831.263 & 0.0000 & 30 & 540 \\
\hline
\end{tabular}

Table 10. The Granger causality test results of agriculture environmental efficiency and economic growth.

\begin{tabular}{ccc}
\hline Null hypothesis: & F-Statistic & Prob. \\
\hline Y does not Granger Cause X & 3.99032 & 0.0015 \\
X does not Granger Cause Y & 3.56600 & 0.0036 \\
\hline
\end{tabular}

Table 11. The regression results of agriculture environmental efficiency and economic growth.

\begin{tabular}{|c|c|c|c|c|c|c|c|c|c|}
\hline Fix & Coefficient & Std. Error & t-statistic & Prob. & Random & Coefficient & Std. error & t-statistic & Prob. \\
\hline $\mathrm{Y}$ & -0.746648 & 0.252388 & -2.958328 & 0.0032 & $\mathrm{Y}$ & -0.050857 & 0.040301 & -1.261940 & 0.2075 \\
\hline YY & 1.511859 & 0.551054 & 2.743576 & 0.0063 & YY & 4.97E-05 & 2.84E-05 & 1.749385 & 0.0808 \\
\hline $\mathrm{C}$ & 97.70853 & 2.550786 & 38.30527 & 0.0000 & $\mathrm{C}$ & 51.95258 & 1.148007 & 45.25459 & 0.0000 \\
\hline \multirow[t]{2}{*}{ R-squared } & 0.506357 & \multicolumn{2}{|c|}{ Adjusted R-squared } & 0.4613 & R-squared & 0.506357 & \multicolumn{2}{|c|}{ Adjusted R-squared } & 0.4613 \\
\hline & & & & & Hausman & \multicolumn{3}{|c|}{11.037963} & 0.0040 \\
\hline
\end{tabular}




\section{Basic Conclusion}

This paper has investigated agriculture environmental efficiency of various provinces in China based on SBM model, and conducted correlation analysis for agriculture environmental efficiency and economic development. Through the study it is found that the mutual Granger causality exists between economic growth and agriculture environmental efficiency. With the economic development, agriculture environmental efficiency is low and we are seeking economic growth with the loss of environmental protection. Change of economic growth is an important reason for nonpoint source pollution and environmental efficiency change. We also found that economic growth and agriculture environmental efficiency are presenting change in " $U$ " shape; agricultural nonpoint source pollution is a result of economic development, and the change of increase and decrease will be presented in different stages of economic development; and the agriculture environmental efficiency will show the change that first decreases and then increases along with the change of agricultural nonpoint source pollution at different stages of economic development. It also has indirectly verified the EKC hypothesis. Only effective control of agricultural nonpoint source pollution is in place, and development and promotion of agricultural technology have been improved. The agriculture environmental efficiency and economic growth can reach the turning point faster, making agriculture environmental efficiency changed to the right side of the "U" shape to achieve sustainable development.

\section{References}

[1] (2010) Agricultural Nonpoint Source Pollution: Watershed Management and Hydrology. CRC Press, Boca Raton.

[2] Gomes, E.G. and Estellita, L.M.P. (2008) Modelling Undesirable Outputs with Zero Sum Gains Data Envelopment Analysis Models. Journal of the Operational Research Society, 59, 616-623. http://dx.doi.org/10.1057/palgrave.jors.2602384

[3] Ongley, E.D., Zhang, X.L. and Yu, T. (2010) Current Status of Agricultural and Rural Non-Point Source Pollution Assessment in China. Environmental Pollution, 158, 1159-1168. http://dx.doi.org/10.1016/j.envpol.2009.10.047

[4] Yang, J., Shao, H.H. and Hu, J. (2010) Empirical Research for China Environmental Efficiency Evaluation and Factors. China Population, Resources and Environment, 20, 49-55.

[5] Su, Y. (2005) Environmental Pollution Issues in Rural Modernization. Frontier Report, 24, 33-35.

[6] Luo, Y. (2012) Study on Index Selection and Environmental Efficiency Evaluation Based on DEA Method. China University of Science \& Technology, Hefei.

[7] Bryan, B.A. and Kandulu, J.M. (2011) Designing a Policy Mix and Sequence for Mitigating Agricultural Non-Point Source Pollution in a Water Supply Catchment. Water Resources Management, 25, 875-892. http://dx.doi.org/10.1007/s11269-010-9731-8

[8] Reinhard, S., Knox Lovell, C.A. and Thijssen, G.J. (2000) Environmental Efficiency with Multiple Environmentally Detrimental Variables; Estimated with SFA and DEA. European Journal of Operational Research, 121, 287-303. http://dx.doi.org/10.1016/S0377-2217(99)00218-0

[9] Coelli, T., Lauwers, L. and Van Huylenbroeck, G. (2007) Environmental Efficiency Measurement and the Materials Balance Condition. Journal of Productivity Analysis, 28, 3-12. http://dx.doi.org/10.1007/s11123-007-0052-8

[10] Marconi, D. (2010) Trade, Technical Progress and the Environment: The Role of a Unilateral Green Tax on Consumption. Bank of Italy Temi di Discussione (Working Paper) No. 744.

[11] Sueyoshi, T. and Goto, M. (2013) Returns to Scale vs. Damages to Scale in Data Envelopment Analysis: An Impact of US Clean Air Act on Coal-Fired Power Plants. Omega, 41, 164-175. http://dx.doi.org/10.1016/j.omega.2010.04.005

[12] Dios-Palomares, R. and Martínez-Paz, J.M. (2011) Technical, Quality and Environmental Efficiency of the Olive Oil Industry. Food Policy, 36, 526-534. http://dx.doi.org/10.1016/j.foodpol.2011.04.001

[13] Li, J. (2008) Environmental Efficiency Evaluation on the Basis of SBM Model. Journal of Hefei University of Technology (Natural Science Edition), 5.

[14] Wang, J.N., Xu, Z.C., Hu, X.B., et al. (2010) The China Regional Environmental Efficiency Analysis Based on DEA Theory. China Environmental Science, 4, 565-570.

[15] Liu, Y., Li, Z.X. and Li, J. (2010) Comparative Study on Environmental Efficiency Evaluation Method. Practice and Knowledge of Mathematics, 1.

[16] Song, M.L., Wang, S.H., Ru, H.P. and Wang, G. (2010) Statistical Analysis on the FDI Green Innovation Ability Based on Provincial Panel Data. China Soft Science, 5, 143-151.

[17] Wang, B., Wu, Y.R. and Yan, P.F. (2010) China Regional Environmental Efficiency and Environmental Total Factor 
Productivity Growth. Economic Research, 5, 95-109.

[18] Liu, R.J. and Zhang, Z.H. (2012) China’s Industrial Economy—Environmental Efficiency Evaluation Based on WTPDEA Method. China Population, Resources and Environment, 2, 22.

[19] Hu, D.S. and Li, Y. (2012) Regional Differences of Environmental Efficiency Evaluation and Its Influencing Factors. Financial Sciences, 4.

[20] Song, M.L. and Wang, S.H. (2013) Environmental Regulation, Technological Progress and Economic Growth. Economic Study, 3, 122-134.

[21] Zhou, W.Q. and Nie, M. (2013) Study on China Provincial Industrial Technical Efficiency of Energy Conservation and Emission Reduction. China Population, Resources and Environment, 23.

[22] Fare, R., Grosskopf, S. and Pasurka Jr., C.A. (2007) Pollution Abatement Activities and Traditional Productivity. Ecological Economics, 62, 673-682. http://dx.doi.org/10.1016/j.ecolecon.2006.08.014

[23] Färe, R., Grosskopf, S., Lundgren, T., et al. (2012) Pollution Generating Technologies and Environmental Efficiency.

[24] Liu, P.F., et al. (2002) The Livestock Excrements Pollution Load of the Yangtze River Delta City and Its Countermeasures. Resources and Environment in Yangtze River Basin, 5, 457-457. 